\title{
Promovendo a cidadania por meio do cuidado de enfermagem
}

\author{
Promoting citizenship through nursing care \\ Promoviendo la ciudadanía por medio de la atención de enfermería
}

\author{
Dirce Stein Backes', Marli Stein Backes", AlacoQue Lorenzini Erdmann" \\ ${ }^{\prime}$ Centro Universitário Franciscano. Santa Maria, RS \\ "Universidade Federal de Santa Catarina. Grupo de Estudos e Pesquisa em \\ Administração de Enfermagem e Saúde. Florianópolis, SC
}

Submissão: 17/01/2009

Aprovação: 22/03/2009

\section{RESUMO}

Estudo é fruto de um projeto de pesQuisa intitulado: Redes de cuidado e empreendedorismo social: a autonomia e o compromisso social do enfermeiro. Trata-se de um estudo Qualitativo Que objetivou compreender o significado do cuidado de enfermagem como prática social empreendedora. Utilizou-se como referencial metodológico a Grounded Theory e como técnica de coleta de dados a entrevista, realizada com 35 participantes. A codificação e análise dos dados conduziram ao tema central: Vislumbrando o cuidado de enfermagem como prática social empreendedora. Esse fenômeno é complementado pela categoria, caracterizada como condição causal: A inserção social por meio da construção de uma identidade política Que expresse o seu envolvimento responsável. Os resultados evidenciaram Que é necessário conhecer e aprender profundamente o princípio da dialógica. Para Que a participação popular se consolide como ideal de cidadania é necessário uma postura profissional crítica, fundamentada na combinação de cuidado com liberdade, participação e autonomia. Descritores: Cuidados de enfermagem; Papel do profissional de enfermagem; Responsabilidade social; PesQuisa em enfermagem.

\section{ABSTRACT}

This study is the result of the project: Networks care and social entrepreneurship: the autonomy and social commitment of nurses. The purpose of this Qualitative study is to comprehend the meaning of nursing care as a social enterprising practice. The Grounded Theory was used as a methodological reference and the interview, conducted with 35 participants as technieue of data collection. Data codification led to the central theme: Viewing Nursing Care as a Social Enterprising Practice. This theme is complemented by the category, characterized the cause condition: The social integration through the creation a political identity that expresses your involvement. The results showed that is necessary to learn and have a deep dialogic knowledge. In order to consolidate popular participation as a citizenship ideal, a critical professional attitude, base don the combination of care with liberty, participation end autonomy.

Descriptors: Nursing care; Nurse's role; Social responsibility; Nursing research.

\section{RESUMEN}

Estúdio es fruto de un proyecto intitulado: Redes sociales y de atención del empresariado: la autonomía y compromiso social de las enfermeras. Se trata de un estudio cualitativo con el objetivo de comprender el significado del cuidado de enfermería como práctica social emprendedora. Se utilizó como metodología a la Grounded Theory y como técnica de recopilación de datos de la entrevista, realizada con 35 participantes. La codificación y el análisis dirigieron el tema central: Vislumbrando el Cuidado de la Enfermería como práctica social emprendedora. Este tema, complementado per la categoría, caracterizada como condición causal: La integración social a través de la construcción de una identidad política que expresa su participación. Los resultados mostraron que es necesario conocer y aprender profundamente el principio de diálogo. Para Que la participación popular se consolide como ideal de la ciudadanía es necesario una postura profesional critica, fundamentada en la combinación de la atención con libertad, participación y la autonomía.

Descriptores: Atención de enfermería; Rol de la enfermera; Responsabilidad social; Investigación en enfermería. 


\section{CONSIDERAÇÕES INICIAIS}

Face à complexidade das Questões sociais emergentes, é premente Que os diferentes setores e profissionais mobilizem-se nos mais variados ambientes, para instaurar novos espaços de participação e desenvolvimento social por meio do ensino, pesQuisa e extensão.

Os profissionais, de modo geral, devem saber driblar as crescentes exigências e fazer delas suas aliadas, procurando descobrir habilidades inovadoras e criativas de intervenção social. É importante Que todos os atores sociais e políticos tenham responsabilidade pessoal e uma nova atitude profissional - uma atitude de mudança, inovadora em sua natureza/essência e voltada para o desenvolvimento da cidadania ${ }^{(1)}$.

Considera-se por - cidadania - um conteúdo de pertença igualitária, representada pelos direitos e deveres dos cidadãos em uma comunidade política, formada por histórias sociais singulares, Que possibilitam ao indivíduo tornar-se sujeito e autor da sua própria história, pela participação ativa e responsável com o desenvolvimento social ${ }^{(2)}$.

Nesse empreendimento, o enfermeiro deve ser capaz de extrapolar os limites do saber disciplinar, dos sistemas institucionalizados com foco na doença e, crescentemente, protagonizar novos espaços e práticas de promoção da cidadania. Em outras palavras, o enfermeiro deve ser capaz de promover um cuidado integral e contextualizado, isto é, um cuidado que vá além da lógica dos processos, das estruturas e dos resultados focados no saber biologicista institucionalizado ${ }^{(3)}$.

A percepção de Que o enfermeiro, por meio do cuidado como prática social, é capaz de contribuir para o desenvolvimento social Que têm a ver com a ampliação dos espaços e oportunidades reais dos seres humanos desenvolverem suas potencialidades, constituise, na atualidade, uma importante estratégia de inclusão social. Os grandes indutores de mudanças sociais nasceram da consciência crítica e visão de mundo, de estratégias inovadoras, projetos ou organizações sociais propositoras de novas metodologias de intervenção social.

Com base nas considerações Questionamo-nos: de Que forma a enfermagem, enQuanto profissão iminentemente social pode estar contribuindo na construção da cidadania? de Que forma a interação pró-ativa dos enfermeiros pode estar contribuindo na inclusão social pela educação e promoção da saúde? de Que forma a enfermagem pode estar implementando políticas sociais e de saúde com vistas à transformação social?

A percepção de Que o enfermeiro pode e é capaz de interagir pró-ativamente no desenvolvimento social local e na ampliação das possibilidades empreendedoras reflete, em última análise, o desejo de fazer a travessia do paradigma biologicista, ainda hegemônico na saúde, para um pensamento sistêmico de intervenção social, capaz de contemplar e considerar o uno e o múltiplo em vez da eficiência apenas individual. Assim, objetivamos com este estudo compreender o cuidado de enfermagem como prática social.

\section{METODOLOGIA}

Trata-se de um estudo com método Qualitativo do tipo Grounded Theory, ou também chamado Teoria Fundamentada em Dados. O estudo é fruto de um projeto de pesquisa ampliado, intitulado: Redes de cuidado e empreendedorismo social: a autonomia e o compromisso social do enfermeiro, Que objetivou compreender o significado da prática social do enfermeiro.

Caracterizada como pesquisa Qualitativa interpretativa, a Grounded Theory vem sendo utilizada internacionalmente com ênfase na área da saúde/enfermagem. Esta considera a multiplicidade das interações sociais e o entendimento global, profundo e complexo acerca da realidade, da vida e da ação humana no mundo real( ${ }^{(4)}$.

O propósito básico da Grounded Theory é desenvolver uma teoria Que tenha relevância na área sob investigação, isto é, Que seja capaz de acrescentar novos dados ao fenômeno sob investigação. Logo, o método busca identificar, desenvolver e relacionar conceitos a partir de vários e diferentes grupos amostrais e gerar uma teoria assentada nos dados empíricos ${ }^{(4-7)}$.

Optou-se, nesse estudo, pela técnica de observação e entrevista em profundidade. No total, a amostra teórica constituiu-se de 35 entrevistas, com a finalidade de maximizar a variação entre os conceitos e acrescentar novas perspectivas ou hipóteses ao fenômeno sob investigação. Assim, o primeiro grupo amostral foi formado por enfermeiros Que atuam em diferentes espaços profissionais, isto é, Universidades, Hospitais, Unidades Básicas de Saúde e outros. O segundo grupo foi formado por profissionais da saúde, ou seja, pelos coordenadores dos cursos da área da saúde da Universidade Federal de Santa Catarina. O terceiro grupo, por sua vez, foi formado por profissionais e usuários que integram um Projeto de Inclusão Social da Grande Florianópolis. Dentre os entrevistados, encontram-se: enfermeiros, médicos, odontólogos, nutricionistas, farmacêuticos, psicólogos, teólogos, pedagogos, gerentes administrativos e usuários.

A coleta e a análise dos dados, processada de forma cíclica e comparativa como prevê a Grounded Theory ${ }^{(8)}$, foi realizada entre maio e dezembro de 2007. O Questionamento Que inicialmente norteou as entrevistas, seguido de outros Que emergiram a partir da análise dados e do advento de novas hipóteses foi: Qual o significado do cuidado de enfermagem como prática social? O método possibilitou construir hipóteses testáveis e gerar construtos teóricos, Que conduziram ao fenômeno: Vislumbrando o cuidado de enfermagem como prática social empreendedora. Esse fenômeno é complementado pela categoria - caracterizada como condição causal: A inserção social por meio da construção de uma identidade política Que expresse o seu envolvimento responsável.

O projeto de tese foi submetido e aprovado pelo Comitê de Ética em Pesquisa da Universidade Federal de Santa Catarina (UFSC), no dia 07 de maio de 2007, sob o número 052/07.

Para manter o anonimato, os participantes da pesQuisa serão identificados, ao longo do texto, com a letra "P", seguida de um algarismo Que corresponde à fala.

\section{RESULTADOS E DISCUSSÃO}

Face às contradições sociais, o enfermeiro está sendo instigado a responder Qual, efetivamente, o seu papel social e como este vem sendo desenvolvido, considerando a premência das interpelações advindas dos mais diferentes espaços e que exigem, gradativamente, uma atitude consciente, responsável e pró-ativa.

Para os entrevistados, em geral, o enfermeiro está aberto e sensível às necessidades da sociedade atual. Necessita, no entanto, 
maior inserção na rede social por meio da construção de uma identidade política Que expresse o seu envolvimento responsável e comprometido, conforme refletem as falas a seguir:

Mesmo com todos os seus avanços sociais, a enfermagem ainda carece de um projeto político Que expresse a sua participação e envolvimento de forma mais expressiva nos problemas sociais (P8).

O enfermeiro avançou na Questão das práticas sociais... falta, no entanto, um projeto político mais amplo Que estimule os enfermeiros a participarem mais ativamente nos problemas sociais (PI7).

No entender dos profissionais da saúde, as discussões acerca das contradições sociais Que envolvem as Questões de cidadania já estão contempladas nas diretrizes curriculares de formação acadêmica. As diretrizes curriculares, mais especificamente da área da saúde, reforçam a necessidade da formação crítica, reflexiva, participativa e empreendedora no campo de intervenção social.

Destaca-se, nesse processo, o empreendedorismo social, entendido como um paradigma emergente de um novo modelo de desenvolvimento em redes e parcerias, com foco na dimensão humana, social e sustentável. Pode ser entendido, também, como um fator indutor e gerador de auto-organização do sistema social, contribuindo para o desenvolvimento integrado e sustentável, bem como no enfrentamento das expressões da Questão social. Caracteriza-se por empregar estratégias dinâmicas no desencadeamento de ações locais com efeito global e impacto social. Nesse sentido, o empreendedorismo social gera transformação social, emancipação social e empoderamento dos cidadãos, contribuindo para a sustentabilidade e justiça social ${ }^{(9)}$.

As diretrizes curriculares precisam, no entanto, reverter-se em ações concretas e no fomento de políticas públicas Que expressem o envolvimento responsável e comprometido com o exercício da cidadania, conforme expressa a fala a seguir:

[...] ao pegar e ler todos os currículos e mesmo as diretrizes curriculares... todos apontam para a formação de um aluno crítico, reflexivo e participativo.... Quando você vai olhar na prática não tem isto. É muito mais importante, ainda, uma aula do que participar de uma reunião do Conselho Municipal de Saúde, do conselho local de saúde. Ou seja, mais uma vez a formação do sujeito enquanto um cara que é competente de forma individual se mostra muito maior do Que aquele sujeito Que se alia e se agrupa em termos de formação de mundo e sociedade (PI2).

Tanto na teoria, Quanto na prática e na representação social de grande parte dos profissionais de enfermagem, a relação com as políticas de saúde e o fomento de atividades pró-ativas e empreendedoras está Quase sempre ausente ${ }^{(9,10)}$. Para os autores, em Questão, embora a enfermagem possua o maior contingente de trabalhadores da saúde, esta ocupa ainda uma posição secundária no Que se refere à participação e execução de atos concretos de promoção da saúde, Que revertam na participação e elaboração de políticas públicas, voltadas para o desenvolvimento social.

Estudos recentes evidenciam, Que o papel do enfermeiro na atual configuração política e social deve ser Questionado, embora existam iniciativas e um esforço mesmo Que isolado por parte dos profissionais $^{(9,11)}$. A enfermagem necessita, na visão dos autores, rever a sua prática e o seu papel social e mostrar concretamente o seu engajamento coletivo nas discussões Que dizem respeito às crescentes injustiças sociais e na saúde. O enfermeiro, como os demais profissionais da saúde, precisam desenvolver uma cultura empreendedora, isto é, explorar novos espaços Que estimulem a participação cidadã pelo desenvolvimento de metodologias ativas focadas no indivíduo como sujeito e autora da própria história.

Muito além dos modelos tradicionais de cuidado ou resolução dos problemas de forma pontual, a promoção da cidadania pressupõe, por parte dos enfermeiros, uma inserção na realidade concreta e o desenvolvimento de processos interativos e pró-ativos Que mostram, concretamente, a participação social. A inserção na rede social por meio da construção de uma identidade política Que expresse o envolvimento responsável e comprometido significa, sob esse enfoque, protagonizar novos espaços e assumir uma postura em defesa da vida, ameaçada pelo modelo econômico hegemônico de globalização ${ }^{(12)}$.

Nessa perspectiva, o empreendedorismo social se constitui numa abordagem sistêmica importante pela possibilidade de promover, por meio das redes solidárias, ações criativas e inclusivas capazes de enfrentar as Questões sociais relacionadas à desigualdade social e a exclusão social ${ }^{(13)}$. É preciso, no entanto, Que os profissionais tenham sensibilidade e abertura para captar os diferentes movimentos contraditórios, Que convivem lado a lado com as chamadas práticas hegemônicas tradicionais. Para os profissionais, de modo geral, é preciso desenvolver competências profissionais para integrar os movimentos contraditórios presentes na sociedade atual e responder de forma crítica e consciente aos desafios atuais.

Entrar na realidade significa, no entender dos profissionais da saúde, estimular práticas empreendedoras inclusivas e desenvolver projetos políticos Que expressem a participação social do enfermeiro nos mais diferentes espaços de atuação profissional. Significa desenvolver uma atitude solidária e, ao mesmo tempo, sentir-se agente transformador com potencialidades reais para intervir ativamente nos problemas Que dizem respeito às necessidades dos indivíduos.

No entender dos entrevistados, o enfermeiro tem possibilidades e potencialidades para colaborar de forma mais ativa na elaboração de políticas de saúde Que contemplem o exercício da cidadania. Por conhecer amplamente o contexto social do usuário da saúde e comunidade, o enfermeiro precisa, no entanto, desenvolver projetos políticos amplos, envolventes e inovadores, a fim de dar visibilidade e sustentabilidade à sua prática social, conforme reflete a fala:

Chegou o momento, em Que o enfermeiro precisa mostrar concretamente a sua prática social e não ficar apenas na dependência das políticas governamentais... A enfermagem precisa ter o seu projeto social próprio... precisa dar visibilidade e sustentabilidade à sua prática (PI9).

[...] me parece que o enfermeiro deveria refletir e pensar mais num projeto nacional e social... deveria pensar num projeto mais amplo e participar mais das políticas de saúde... Eu vejo alguns projetos muito conservadores e pouco criativos e inovadores. Eu creio que este é um debate que deveria se promover. Isto é, que tipo de projeto está se promovendo a nível regional, nacional e em nível da América Latina (P2 I). 
O desenvolvimento de projetos políticos Que expressem a participação social do enfermeiro possibilita, de acordo com os entrevistados, além de um maior engajamento social, uma expressão de inconformidade face às injustiças crescentes. A inconformidade é expressa, pelos entrevistados, como forma de "indignação" ou "auto-perturbação" diante da problemática social.

O exercício da cidadania é compreendido pelos entrevistados como um processo de emancipação do sujeito e o protagonismo de ações pró-ativas voltadas para a educação e promoção da saúde. Em outras palavras, ações Que gerem a melhoria na expectativa de vida das pessoas e o desenvolvimento de seu potencial ${ }^{(14)}$.

O impacto das ações sociais empreendedoras depende, portanto, não apenas da habilidade em identificar as oportunidades, mas, principalmente, da capacidade de conviver em meio à pluralidade de saberes e envolver o maior número de atores sociais na criação de espaços interativos de construção da cidadania ${ }^{(13)}$. Os entrevistados corroboram com a afirmativa, ao evidenciarem Que o exercício da cidadania não depende unicamente da capacidade de inovar ou protagonizar novos espaços, mas da habilidade de acolher e integrar as contingências do tempo e do momento, mesmo Que contraditórias e desestabilizadoras, como seguem as reflexões a seguir:

As ações rebeldes dos adolescentes traficantes podem ser consideradas ações perturbadoras Que visam chamar a atenção da sociedade para dizer Que as coisas como estão não podem continuar assim (P3I).

Claro, isto perturba... ninguém aceita o tráfico, as drogas... mas eles estão aí. Com isto os jovens Querem dizer Que não concordam mais com aQuela escola... Este jovem que está aí, ele está dizendo o Que não está certo na sociedade. Eu não Quero esta escola. Eu fico doente se eu ficar aí. Claro, que a escola? Que serviço de saúde?. (P33).

As influências do entorno social, ao mesmo tempo em Que mostram a face sóbria de uma sociedade doente, mostram, também, Que a enfermagem está inserida ativamente na rede de interações por meio da acolhida e compreensão do indivíduo em seu contexto real. Essa dinâmica pode ser evidenciada à medida que a enfermagem se abre às novas possibilidades interativas e se mobiliza para compreender e acolher o indivíduo como um ser uno, complexo e multidimensional.

No entender dos entrevistados, a enfermagem, se comparada aos demais profissionais da saúde, tem uma atuação mais próxima e comprometida com as necessidades da população. É o profissional Que melhor consegue acolher e compreender a vulnerabilidade humana. Os mesmos ressaltaram, também, Que a enfermagem por meio do cuidado consegue compreender o indivíduo como um todo.

[...] O enfermeiro é mais Que um especialista... ele consegue olhar para o todo e não apenas a parte... ele consegue ocolher o indivíduos nas diferentes situações (P29);

[...] É o enfermeiro que diz o que deve ser feito e onde o jovem deve ser encaminhado (P34).

Dentre os profissionais da saúde, a enfermagem é Quem melhor compreende o indivíduo em suas necessidades... a enfermagem sabe acolher as diferentes situações (P34).

A enfermagem e nem mesmo o setor da saúde, podem ficar alheias às discussões Que envolvem as contingências sociais emergentes. Mais do Que uma Questão de responsabilidade social, esta é, também, um dever de cidadania e uma Questão ética para com o ser humano ${ }^{(14)}$.

Promover a cidadania por meio do cuidado de enfermagem significa, a partir do exposto, compreender os movimentos contraditórios e paradoxais de ordem, desordem e caos, como possibilidades para a construção de uma nova ordem social(16). Significa exercer o exercício da indignação, da escuta atenta, do diálogo aberto e do olhar sensível para detectar as reais necessidades da população. Implica em promover a cidadania por meio do ensino, da pesquisa e da extensão, sustentando a teoria pela prática e a prática pela teoria.

Lidar estrategicamente com as certezas e incertezas, com a instabilidade e a desordem do entorno social, significa integrar as contradições do dia-a-dia enquanto propulsoras de novas possibilidades interativas ${ }^{(17)}$. Para o autor, em Questão, as perturbações e interpelações em forma de ruídos, são elementos imprescindíveis para a (co)evolução do sistema e a promoção da cidadania como bem-estar social.

Por meio do cuidado de enfermagem como prática social, não temos como acrescentar mais dias de vida à população, mas podemos relativizá-los, em nossa interação com eles, em seu processo de vida, no reconhecimento e potencialização desse vitalismo Que lhes é próprio. Esse vitalismo, onde reside a potência da vida comum, onde se inscreve a estética desse ser saudável. Nesse Quotidiano, onde se sobrevive na alegria e na tristeza, no amor e no ódio, no prazer e na dor, no trabalho e no lazer, no riso e no choro, no ser e estar junto Que relativiza esse viver ${ }^{(18)}$.

Muito além dos discursos teóricos e programas de socorro à pobreza, a promoção da cidadania pelo cuidado de enfermagem envolve uma abordagem dialógica, isto é, o diálogo com o mundo ${ }^{(16)}$ ou o diálogo com o entorno social ${ }^{(17)}$. Promover a cidadania a partir de uma concepção dialógica com o mundo concreto, significa potencializar os elementos vitais Que garantem a auto-organização dos grupos sociais específicos, sem ferir/agredir a organização particular. De outro modo, promover a cidadania, sem considerar a organização particular dos indivíduos ou comunidades, entendida somente a partir da dialógica, significa mutilar o Que lhes resta de mais vital - a sua própria organização e vitalismo.

Mesmo que exista um contexto favorável Que evidencia espaços múltiplos da organização social do cuidado de enfermagem e interveniências político-pedagógicas Que sinalizam para uma nova abordagem de intervenção social, existe de outro modo, a necessidade de superar as barreiras culturais, bem como as práticas hegemônicas e tradicionais de cuidado, ainda, fortemente focadas na doença.

É preciso Que a enfermagem potencialize, cada vez mais, os recursos e competências dos próprios indivíduos, possibilitando a transformação social por meio das ações de saúde integradas e articuladas em redes, isto é, pela ampliação das oportunidades interativas e práticas pró-ativas e empreendedoras de impacto global $^{(9)}$. Ampliar a intervenção social pela promoção da cidadania implica, nessa direção, ampliar campo de atuação social, onde as 
chances de inovar, criar e estabelecer parcerias são maiores e cujos resultados estão mais diretamente relacionados com a promoção e educação da saúde.

Enfim, compreender a enfermagem como prática social empreendedora, comprometida com a construção da cidadania, significa compreendê-la como uma profissão dinâmica, inovadora, aberta às transformações permanentes e, acima de tudo, inserida num processo de trabalho Que produz serviços em saúde e cujo produto final é o cuidado de enfermagem à pessoa no seu processo saúde-doença ${ }^{(19)}$.

\section{CONSIDERAÇÕES FINAIS}

O enfermeiro possui um leque de possibilidades amplo e complexo para exercer e promover a cidadania por meio do cuidado. Possui um campo aberto nos diferentes espaços e contextos, contudo, esses necessitam gradativamente serem explorados, a fim de apreender e responder de forma concreta e abrangente às contradições sociais emergentes.

O investimento na promoção e educação da saúde comunitária, diferentemente das práticas institucionalizadas tradicionais, possibilita ampliar as relações e interações pelo vínculo com os usuários da saúde, famílias e comunidades. Possibilita fortalecer a democracia e a autonomia, tanto do profissional Quanto do usuário. Possibilita um sentimento de maior satisfação e realização profissional.

Apesar do contexto favorável Que evidencia espaços múltiplos da organização social do cuidado de enfermagem, a inserção social por meio da construção de uma identidade política Que expresse o seu envolvimento responsável, identificada como condição causal, evidencia Que o sistema, QualQuer Que seja ele, precisa estar atento às perturbações do entorno social. Para manter a dinâmica organizacional e os espaços de atuação profissional, o sistema precisa estar aberto e sensível às perturbações do entorno para continuamente renovar-se e, consequentemente, possibilitar novas e sempre mais complexas comunicações de sentido. O enfermeiro necessita, crescentemente, ampliar a sua inserção pela participação ativa e efetiva no planejamento e desenvolvimento de políticas Que buscam a inserção do indivíduo na coletividade, mediada por ações pró-ativas Que buscam a autonomia do pensar. Necessita compreender e respeitar a complexidade da realidade da forma como ela se apresenta. Significa descobrir a organização específica de cada indivíduo, potencializá-la e apoiar-se nela para educar e cuidar em saúde como exercício de construção da cidadania.

Os resultados permitem concluir, em suma, Que a promoção da cidadania pelo cuidado de enfermagem, está voltada para o resgate da dignidade humana Que se promove mediante atitudes profissionais responsáveis, ousadas, criativas, inovadoras e engajadas de forma ativa e participativa nos espaços sociais de saúde/cuidado. A promoção da cidadania se traduz, nesse sentido, em gestos solidários, na capacidade de negociar com as incertezas, de dialogar com o diferente, na capacidade de ampliar as oportunidades para Que o indivíduo se torne protagonista da sua própria história.

\section{REFERÊNCIAS}

I. Melo Neto FP, Froes C. Empreendedorismo social: a transição para a sociedade sustentável. Rio de Janeiro: Qualitymark; 2002.

2. Santos BS. Pelas mãos de Alice o social e o político na pósmodernidade. São Paulo: Cortez; 2000.

3. Vargas MA, Alburquerque GL, Erdmann AL, Ramos FRS. Onde (e como) encontramos a Qualidade no serviço de enfermagem hospitalar? Rev Bras Enferm 2007; 60(3): 339-43.

4. Strauss A, Corbin I. Basics of Qualitative research: grounded theory - procedures and technieues. California: Sage Publication; 1990.

5. Strauss A, Corbin J. Bases de la investigación cualitativa. Técnicas y procedimientos para desarrollar la teoría fundamentada. Medelin: Universidad de Antioeuia; 2002

6. Strauss A. Pesquisa Qualitativa: técnicas e procedimentos para o desenvolvimento de teoria fundamentada. Porto Alegre (RS): Artmed; 2008.

7. Glaser BG. The Grounded Theory Perspective III: Theoretical Coding, Mill Valley: Sociology Press; 2005.

8. Corbin I, Hildenbrand B. Qualitative Forschung. In: Allhoff R, Schaeffer D, organizadores. Handbuch Pflegewissenschaft. München: Juventa; 2003. p. 159-84.

9. Backes DS. Vislumbrando o cuidado de enfermagem como prática social empreendedora [tese]. Florianópolis (SC): Programa de Pós-Graduação em Enfermagem, Universidade Federal de Santa Catarina; 2008.
10. Costa GMC. Uma abordagem da atuação histórica da enfermagem em face das políticas de saúde. Rev Mineira Enferm 2006; 10(4): 412-7.

I1. Bauer U, Büscher A. Soziale Ungleichheit und Pflege: Konzeptionelle Zugänge. Deuts Zeitsch Pfleg 2007; 12(4): 304- 17.

12. Murad A. Gestão e espiritualidade: uma porta entreaberta. São Paulo: Paulinas; 2007.

13. Oliveira EM. Empreendedorismo social no Brasil: atual configuração, perspectivas e desafios - notas introdutórias. Rev FAE 2004; 7(2): 9-18.

14. Kliksberg B. Falácias e mitos do desenvolvimento social. São Paulo: Cortez; 2001.

15. Martins PH. Ação Pública, redes e arranjos familiares. In: Fontes B, Martins PH, organizadores. Redes, Práticas Associativas e Gestão Pública. Recife: Ed. Universitária da UFPE; 2006. p. 19-50.

16. Morin E. Ciência com consciência. Rio de Janeiro: Bertrand Brasil; 2003.

17. Luhmann N. Sistemas Sociales. Lineamentos para una teoría general. Barcelona: Anthropos; 1998.

18. Penna CM. Ser saudável no Quotidiano da favela. Pelotas (RS): Ed. universitária/UFPEL; 1997.

19. Trezza MCAF, Santos RM, Leite IL. Enfermagem como prática social: um exercício de reflexão. Rev Bras Enferm 2008; 6 I (6) 904-8. 